\title{
Transport properties in a mixed inorganic ion exchanger-zirconium phosphomolybdate--in comparison to its single salt counterparts
}

\author{
B BEENA and UMA CHUDASAMA \\ Department of Chemistry, Faculty of Science, MS University of Baroda, Baroda 390002 , \\ India \\ MS received 4 May 1995
}

\begin{abstract}
Amorphous inorganic ion exchangers zirconium phosphate, zirconium molybdate and zirconium phosphomolybdate have been prepared and characterized by elemental analysis, TGA, FTIR and surface area measurements. The protonic conductivity in these materials were determined at various temperatures and compared. It was found that the mixed material zirconium phosphomolybdate showed maximum conductivity at all temperatures.
\end{abstract}

Keywords. Inorganic ion exchangers; protonic conduction; specific conductance.

\section{Introduction}

In recent years there has been intense research aimed at discovering new proton conductors and the mechanism of conduction in solids. This renewed activity has been driven by the potential use of such compounds in fuel cells, sensors, water electrolysis units and other electrochemical devices.

Inorganic ion exchangers have been extensively studied in the field of separation science and catalysis. But of late attempt has been made to study the transport properties of these materials (Alberti et al 1978, 1979). These materials have the property of protonic conduction and the mechanism of diffusion and ionic transport in crystalline $\alpha$-zirconium phosphate has been studied in detail (Alberti et al 1979). They have the general formula $\mathrm{M}(\mathrm{IV})\left(\mathrm{HXO}_{4}\right)_{2} \cdot n \mathrm{H}_{2} \mathrm{O}$ where $\mathrm{M}=\mathrm{Zr}, \mathrm{Ti}, \mathrm{Ce}$ etc. and $\mathrm{X}=\mathrm{P}$, $\mathrm{As}, \mathrm{Sb}$ etc. The number of water molecules depend upon the method of preparation, drying conditions etc. They have structural hydroxyl protons which are responsible for their ion exchange behaviour. When these $-\mathrm{OH}$ groups are hydrated, the protons can easily move on the surface, thus accounting for their conductivities which depend strongly on relative humidity, the surface area and the degree of crystallinity (Clearfield and Berman 1981).

It has been proved that specific conductance of inorganic ion exchangers increase with decreasing crystallinity, which is in agreement with the expectation that the ionic conductance of a solid increases with increase in the number of defects in the crystalline surface (Alberti et al 1978). Also it has been found that amorphous materials have more surface area than that of crystalline materials (Clearfield and Berman 1981).

Since until now only single salts, especially $\alpha$-zirconium phosphate, was studied in detail for the transport properties, it was thought of interest to study the protonic conduction in a mixed material. In the present study, we have prepared and characterized a typical mixed material, amorphous zirconium phosphomolybdate, its transport properties investigated and compared with that of the corresponding amorphous single salts, zirconium phosphate and zirconium molybdate. 


\section{Experimental}

\subsection{Preparation of the materials}

Zirconium phosphate ( $\mathrm{ZrP})$ and zirconium molybdate $(\mathrm{ZrMo})$ were prepared by methods reported earlier (Beena and Chudasama 1995; Shivanekar and Chudasama 1990). Zirconium phosphomolybdate (ZrPMo) was prepared by mixing zirconyl chloride, trisodium orthophosphate and ammonium molybdate in $1: 1: 1$ mole ratio with continuous stirring. The gel thus obtained was kept at room temperature overnight, filtered, washed with conductivity water and dried at $45^{\circ} \mathrm{C}$ in an oven.

The materials after drying were sized by sieving and converted to the hydrogen form by immersion in $1 \mathrm{M} \mathrm{HCl}$, the acid being intermittently replaced, washed till free from the acid and dried again at $45^{\circ} \mathrm{C}$ and stored at a relative humidity of $\sim 80 \%$.

\subsection{Elemental analysis}

The samples have been analysed for zirconium, molybdenum and phosphorus. Zirconium, molybdenum and phosphorus were determined gravimetrically as zirconium oxide (by cupferron method), molybdenum oxide (by $\alpha$-benzoin oxime method) and phosphorus as magnesium pyrophosphate respectively.

\subsection{Thermal analysis}

The thermogravimetric analysis of samples were performed on a Shimadzu DT $=30$ thermal analyzer, at a heating rate of $10^{\circ} \mathrm{C} / \mathrm{min}$.

\section{$2.4 \quad$ FTIR spectra}

FTIR spectra of the samples were performed using a $\mathrm{KBr}$-wafer on a Perkin-Elmer FTIR model $1720 \times$ with Epson Hi 80 Printer/Plotter.

\subsection{Surface area measurements}

The surface area of the materials were measured by the nitrogen adsorption BET method and recorded on a Carlo-Erba Sorptomatic series -1800 at $-196^{\circ} \mathrm{C}$.

\subsection{Determination of ion exchange capacity (i.e.c.)}

The i.e.c. of the materials was determined as usual by the column method, by taking $1 \mathrm{~g}$ of the exchanger in $\mathrm{H}^{+}$form in a glass column and eluting with $\mathrm{Na}^{+}$ions. The hydrogen ions thus eluted were determined titrimetrically against standard $\mathrm{NaOH}$.

\subsection{Conductivity measurements}

The electrical conductivity of the solids were measured using pellets of $10 \mathrm{~mm}$ diameter and $1.5-2 \mathrm{~mm}$ thickness with a relative humidity of $\sim 80 \%$. The opposite sides of the 


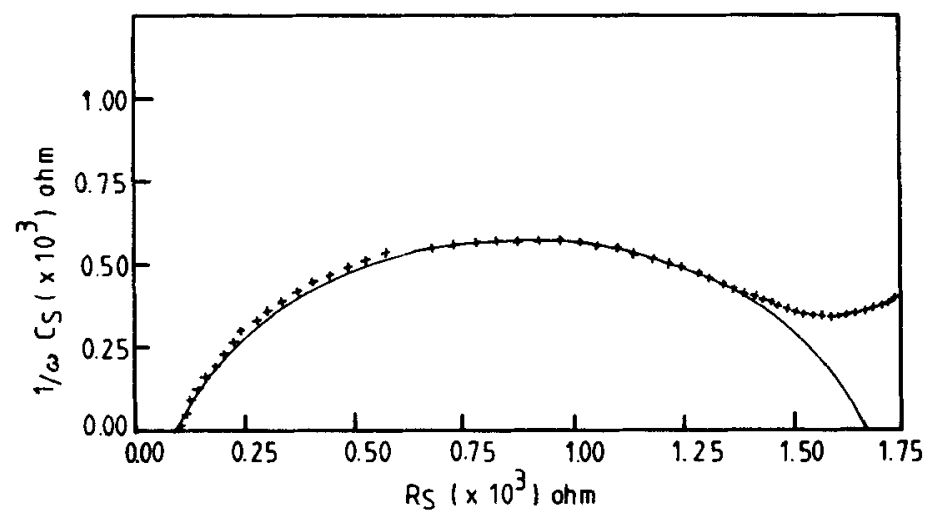

Figure 1. Complex impedance diagram for $\mathrm{ZrPMo}$ at $25^{\circ} \mathrm{C}$.

pellets were coated with conducting silver paste to ensure good electrical contacts. Impedance measurements were taken by using SOLARTON SI 1260 impedance analyser, over a frequency range of $10 \mathrm{~Hz}$ to $32 \mathrm{MHz}$ at a signal level below $1 \mathrm{~V}$, interfaced to a mini computer for data collection. In all cases, since the impedance plots of the materials consist of single depressed semi circle (figure 1), the pellet conductivity was calculated by arc extrapolation to the real axis, taking into account the geometrical sizes of the pellets. The measurements were made in the temperature range of $25-150^{\circ} \mathrm{C}$.

\section{Results and discussion}

All the three materials $\mathrm{ZrP}, \mathrm{ZrMo}$, and $\mathrm{ZrPMo}$ obtained were white, hard and amorphous in nature. The materials were found to be stable in dilute mineral acids like $\mathrm{HCl}, \mathrm{H}_{2} \mathrm{SO}_{4}, \mathrm{HNO}_{3}$ and bases like $\mathrm{NaOH}$ and $\mathrm{KOH}$ up to $4 \mathrm{M}$ concentration, and in ethanol, acetic acid and $1 \mathrm{M}$ salt solutions.

Chemical analyses indicate the composition of $\mathrm{ZrP}, \mathrm{ZrMo}$ and $\mathrm{ZrPMo}$ to be 1:2,1:1 and $1: 1: 1$ respectively. Based on these the formula proposed for these compounds are $\mathrm{ZrO}_{2} \mathrm{P}_{2} \mathrm{O}_{5} \cdot 7 \mathrm{H}_{2} \mathrm{O}, \mathrm{ZrO}_{2} \mathrm{MoO}_{4} \cdot 15 \mathrm{H}_{2} \mathrm{O}$ and $\mathrm{ZrO}_{2} 1 / 2 \mathrm{P}_{2} \mathrm{O}_{5} \mathrm{MoO}_{4} \cdot 15 \mathrm{H}_{2} \mathrm{O}$ for $\mathrm{ZrP}$, $\mathrm{ZrMo}$ and $\mathrm{ZrPMo}$ respectively. The number of water molecules were determined from the thermograms of the samples using Alberti's formula (Alberti and Torracca 1968). The $\mathrm{Na}^{+}$exchange capacities of $\mathrm{ZrP}, \mathrm{ZrMo}$ and $\mathrm{ZrPMo}$ were found to be 1.01, 1.02 and $1.10 \mathrm{meq} / \mathrm{g}$ respectively.

Thermograms of all the materials showed sharp changes within the temperature range of $80^{\circ}-120^{\circ} \mathrm{C}$ corresponding to the loss of external water molecules after which slow change in weight was observed till $600^{\circ} \mathrm{C}$. This may be due to the condensation of structural hydroxyl groups.

FTIR spectra of all the materials showed broad bands in the region $\sim 3400 \mathrm{~cm}^{-1}$. This was attributed to the asymmetric and symmetric hydroxo $-\mathrm{OH}$ and aquo $-\mathrm{OH}$ stretches. A sharp medium band at $\sim 1620 \mathrm{~cm}^{-1}$ was also observed in all the cases which was attributed to the aquo- $(\mathrm{H}-\mathrm{O}-\mathrm{H})$ bending. In addition to these bands the FTIR spectrum of ZrMo showed a broad shoulder at $935 \mathrm{~cm}^{-1}$ which was attributed to the presence of zirconium oxygen stretching. FTIR spectrum of $\mathrm{ZrP}$ showed a sharp medium band at $\sim 970 \mathrm{~cm}^{-1}$ and a broad shoulder at $\sim 1120 \mathrm{~cm}^{-1}$ indicating the 
Table 1. Variation of specific conductance $(\sigma)$ with temperature.

\begin{tabular}{lccc}
\hline & \multicolumn{3}{c}{$\sigma(\Omega \mathrm{cm})^{-1}$} \\
Temp. & ZrP & ZrMo & ZrPMo \\
\hline C & $2.78 \times 10^{-6}$ & $1.12 \times 10^{-5}$ & $1.96 \times 10^{-4}$ \\
25 & $2.63 \times 10^{-6}$ & $1.08 \times 10^{-5}$ & $7.49 \times 10^{-5}$ \\
30 & $7.28 \times 10^{-7}$ & $1.23 \times 10^{-6}$ & $5.87 \times 10^{-5}$ \\
60 & $1.36 \times 10^{-7}$ & $5.20 \times 10^{-7}$ & $1.41 \times 10^{-6}$ \\
90 & $9.27 \times 10^{-8}$ & $3.39 \times 10^{-8}$ & $6.37 \times 10^{-7}$ \\
120 & $3.10 \times 10^{-8}$ & $1.36 \times 10^{-8}$ & $1.77 \times 10^{-7}$ \\
150 & & & \\
\hline
\end{tabular}

presence of asymmetric and symmetric phosphate vibrations. A weak shoulder at $530 \mathrm{~cm}^{-1}$ may be attributed to the zirconium-oxygen stretching. The FTIR spectrum of ZrPMo shows two broad shoulders at $\sim 935 \mathrm{~cm}^{-1}$ and $\sim 1120 \mathrm{~cm}^{-1}$ indicating the presence of zirconium-oxygen stretching and symmetric phosphate vibrations.

Surface area of $\mathrm{ZrP}, \mathrm{ZrMo}$ and $\mathrm{ZrPMo}$ are $48 \mathrm{~m}^{2} / \mathrm{g}, 25 \mathrm{~m}^{2} / \mathrm{g}$ and $55 \mathrm{~m}^{2} / \mathrm{g}$ respectively.

The presence of protons able to be exchanged and hence able to diffuse through the interspaces, make these materials protonic conductors. It is seen that the value of specific conductivity $(\sigma)$ of $\mathrm{ZrPMo}$ at $25^{\circ} \mathrm{C}$ is $1.96 \times 10^{-4} \Omega^{-1} \mathrm{~cm}^{-1}$ whereas for the corresponding single salts $\mathrm{ZrP}$ and $\mathrm{ZrMo}$ the value of $\sigma$ is $2.78 \times 10^{-6}$ and $1 \cdot 12 \times 10^{-5} \Omega^{-1} \mathrm{~cm}^{-1}$ respectively. For all these materials specific conductivity decreases with increasing temperature (table 1). This is due to the gradual loss of water of hydration as well as the condensation of structural - $\mathrm{OH}$ groups. This also suggests the mechanism of transportation as a Grothus type (Clearfield 1988) where the conductivity depends on the ability of water located on the surface to rotate and participate in a Grothus type transport. This also agrees with the suggestion that protons are not able to diffuse along an anhydrous surface where the spacing of the $-\mathrm{OH}$ groups is high (Alberti et al 1989). Also the fact that the loss of protons resulting from hydroxyl condensation causes a considerable decrease in conductivity indicates that the electrical conduction is protonic also.

The high value of specific conductance in $\mathrm{ZrPMo}$ which is of the order of $10^{-4} \Omega^{-1}$ $\mathrm{cm}^{-1}$ is comparable to that of amorphous polymer electrolyte blends prepared by blending poly (propyleneglycol) with poly (ethylene oxide) - NaI electrolyte (Paulmer and Kulkarni 1992). This high value of specific conductance in ZrPMo as compared to the single salts $\mathrm{ZrP}$ and $\mathrm{ZrMo}$ may be because of its comparatively large surface area. It has been shown earlier in zirconium phosphate that conductivity increases with increase in surface area (Alberti et al 1978). The value of $\sigma$ in ZrPMo is only one order less than that of pellicular zirconium phosphate and colloidal dispersion of $\alpha-\mathrm{ZrP}$ $\left(\sigma \sim 10^{-3} \Omega^{-1} \mathrm{~cm}^{-1}\right)$ where the preparation methods are rather difficult (Alberti et al 1989). Thus ZrPMo with its easy method of preparation and relatively high value of specific conductance offers as a promising material for solid electrolyte applications.

\section{Conclusions}

Zirconium phosphomolybdate exhibits better transport properties than the corresponding single salts prepared under the same conditions. The conductivity is essentially 
dependent on the surface water of hydration. ZrPMo with its easy method of preparation and comparatively high value of specific conductance is a promising material for solid electrolyte applications.

\section{Acknowledgements}

Thanks are due to the Head, Department of Chemistry for providing necessary laboratory facilities. The help rendered by Dr A R Kulkarni, IIT, Bombay in impedance measurements is gratefully acknowledged. One of us $(\mathrm{BB})$ is also thankful to UGC, New Delhi for financial assistance.

\section{References}

Alberti G and Torracca E 1968 J. Inory. Nucl. Chem. 303075

Alberti G, Casciola M, Costantino U, Levi G and Riccardi G 1978 J. Inorg. Nud. Chem. 40533

Alberti G, Casciola M, Costantino U and Radi R 1979 Ga:=. Chim. Itat 109421

Alberti G, Casciola M. Costantino U and DiGregono F 1989 Solid State Ionics $32 / 3340$

Beena B and Chudasama U 1995 Trans. Met. Chem. 20166

Clearfield A and Berman J R 1981 J. Inorg. Nucl. Chem. 432141

Clearfield A 1988 Chem. Rev. 88125

Paulmer R D A and Kulkarni A R 1992 Solid state ionics: materials and applications (ed) B V R Chowdari (Singapore: World Scientific) p. 549

Shivanekar A and Chudasama U 1990 Trans. Met. Chem. 15222 